\title{
A METAFÍSICA DO OLHAR: BREVE INTERLOCUÇÃO COM SARTRE, MERLEAU-PONTY E LACAN
}

Paulo de Carvalho Ribeiro

Médico e psicanalista. Doutor em psicanálise e psicopatologia, Universidade Paris 7.

Professor do Programa de Pós-Graduação em Psicologia da UFMG.

\begin{abstract}
RESUMO: Partindo da constatação de que o olhar do outro tem uma participação destacada nos primeiros momentos da constituição psíquica, propõe-se uma hipótese sobre a imitação do olhar como fator determinante na constituição do eu. Para fundamentar essa hipótese, discutem-se alguns aspectos das teorias de Sartre, MerleauPonty e Lacan sobre o olhar, colocando-se em destaque os pontos de aproximação e distanciamento entre eles. Uma compreensão original do olhar como objeto a é apresentada a título de breve interlocução com os autores mencionados.
\end{abstract}

Palavras-chave: Olhar, constituição do eu, Imitação.

ABSTRACT: The metaphysics of the gaze: short dialogue with Sartre, Merleau-Ponty and Lacan. Taking as a starting point the important role played by the gaze of the other in early psychic development, this article presents a hypothesis about the imitation of the gaze as a key element in the constitution of the ego. The grounds for this hypothesis are searched for in some aspects of three different theories of the gaze: those of Sartre, Merleau-Ponty and Lacan. The article explores the convergences and disagreements among these authors and proposes, as a form of dialogue with them, an original understanding of Lacan's concept of the gaze as object $a$.

Keywords: The gaze, ego constitution, imitation. 
0 s fenômenos especulares e sua importância na constituição psíquica sempre despertaram grande interesse entre os psicanalistas. O conceito de narcisismo, introduzido por Freud em 1914, e o estádio do espelho, descrito por Lacan em 1936, são marcos teóricos que desempenham papel determinante nas teorias da identificação, da formação do eu e da agressividade, para citar apenas os desdobramentos mais significativos. Ainda no âmbito dos fenômenos especulares, mas considerando agora o campo das neurociências, a descoberta dos neurônios espelho $^{1}$ (RIZZOLATI, FOGASSI \& GALLESE, 2000; 2001), no início dos anos 1990, causou grande impacto e rapidamente produziu importantes repercussões entre os psicólogos cognitivistas e demais estudiosos do desenvolvimento psíquico. Os fenômenos de imitação, que já ocupavam lugar de destaque nas teorias do desenvolvimento e em diferentes abordagens clínicas do autismo infantil, adquiriram ainda mais importância a partir dessa descoberta. Embora tenham uma relação direta com o narcisismo e a constituição do eu, esses fenômenos de imitação receberam pouca atenção dos psicanalistas, com algumas poucas exceções, como é o caso do psicanalista italiano Eugenio Gaddini (1969), que publicou trabalhos pioneiros sobre esse tema, já em meados do século passado. Se levarmos em consideração que a descoberta dos neurônios espelho permite supor que boa parte, ou até mesmo todo o cérebro, pode funcionar como um espelho - como assinala Franco Scalzone (2005), num artigo instigante sobre psicanálise e neurociências — torna-se evidente que as teorias psicanalíticas sobre os fenômenos especulares e sua participação na constituição psíquica devem ser retomadas e eventualmente reformuladas em vista desses novos fatos.

\footnotetext{
${ }^{1}$ Trata-se de sistemas neurais encontrados em determinadas localizações cerebrais de macacos (macaque monkeys) e de humanos, que são ativados seja durante a realização de determinadas ações (tanto de movimentos voluntários, como a apreensão manual de objetos e alimentos, como também nas reações reflexas, como as contrações faciais associadas à repugnância a odores desagradáveis), seja durante a observação dessas mesmas ações quando são realizadas por outros. São, portanto, neurônios dotados de propriedades audiovisuais e motoras, o que os torna particularmente adaptados a desempenhar um papel na imitação. Na verdade, mais do que propiciar os fenômenos imitativos involuntários, a capacidade de capturar uma sequência de imagens de uma ação dotada de sentido, associando-a de maneira direta e automática com os disparos responsáveis pela realização motora da mesma sequência, configura uma condição neural desenhada sob medida para favorecer, ou mesmo permitir, a interação com o mundo externo em geral e com os outros, os semelhantes, em particular. Isso explica que um dos desdobramentos mais importantes da descoberta dos neurônios espelho se dê, precisamente, no campo das relações interpessoais, por meio de teorias sobre o papel desses neurônios na apreensão das intenções alheias, na promoção de laços sociais fundados na capacidade de empatia, na aquisição de linguagem e de habilidades motoras variadas, assim como na constituição do autismo infantil, sendo que neste último caso estariam em jogo as falhas no funcionamento desses neurônios. Para um conhecimento um pouco mais abrangente sobre a descoberta desses neurônios e suas principais consequências no campo das neurociências, remetemos o leitor interessado ao seguinte artigo: GAWRYSZEWSKI et al. (2006) Neurônios espelho. Psicologia USP, 17(4), 123-133.
} 
De nossa parte, uma pesquisa que realizamos sobre a imitação nos conduziu à tentativa de articulação entre os processos imitativos precoces, a constituição do eu e os neurônios espelho. No presente artigo, elegemos o olhar como objeto de estudo, uma vez que o consideramos um elemento decisivo nessa empreitada de retomar o tema da constituição psíquica a partir dos fenômenos especulares. Todo o desenvolvimento que pretendemos apresentar em seguida sobre o olhar parte da seguinte hipótese, que julgamos necessário explicitar desde já: a constituição do eu requer a imitação do olhar do outro antes da existência de uma instância psíquica à qual se possa atribuir a capacidade de olhar ou a intenção de imitar. O conceito lacaniano de objeto a e algumas elaborações de Sartre e Merleau-Ponty sobre o olhar nos ajudarão a justificar a formulação dessa hipótese.

O olhar ocupou um lugar destacado nos pensamentos de Sartre e MerleauPonty. Lançaremos mão de algumas ideias desses autores com o intuito de tomarmos posição com relação às considerações de Lacan sobre o mesmo tema, sem deixar de sopesar que este último autor dialoga com os dois primeiros, chegando a discordar explicitamente de Sartre num ponto decisivo, a partir do qual pretendemos introduzir nossas próprias avaliações. Comecemos nosso pequeno percurso pelas teorias desses três autores, destacando uma curiosa referência de Lacan ao mimetismo, no momento que ele desenvolvia sua tese sobre o olhar como objeto a.

Depois de se valer das considerações de Callois para refutar a tese do mimetismo como mecanismo de adaptação, Lacan (1973b, p.85-87) formula a questão que lhe parece fundamental: seria possível ver no fenômeno natural do mimetismo, tal como o observamos em alguns animais, uma potência formativa do próprio organismo? E quais seriam os circuitos pelos quais esta potência chega a dominar não apenas a forma do organismo a ser mimetizado, mas também sua relação com o meio, permitindo, assim, que o mimetismo aja no sentido de camuflar ou de destacar o animal que a ele se submete? Estas são questões de fato fundamentais, pois, ao sugerir a existência de uma potência formativa, Lacan parece supor que o mimetismo seja uma propriedade de determinados tecidos vivos, capaz de assegurar uma afetação pelo meio externo, decisiva para a constituição do próprio organismo. É o que pode ser confirmado quando, ao comentar o efeito dos ocelos sobre predadores e vítimas, ele não só distingue a função do olho da função do olhar, como também assinala a pré-existência do “dado a ver” (donné à voir) sobre o próprio olhar. Parece haver aqui uma indicação de que, antes de ser capaz de olhar, o olho é dado a ver, atrai o olhar do outro (como os ocelos) e é submetido, assim, a um olhar que, como buscaremos mostrar adiante, ainda não pode produzir reciprocidade — um olhar que incide sobre um olho ainda incapaz de olhar, mas nem por isso imune à imagem dos olhos que o miram e que o levarão, por mimetismo, à condição de poder olhar. 
Se nos deslocarmos agora do domínio do mimetismo observável em determinados animais, e que poderíamos qualificar como corporal (na medida em que afeta a superfície corporal de maneira total ou parcial), para nos situarmos no domínio mais restrito do mimetismo como fenômeno neurológico, poderemos propor, em paralelo às formulações de Lacan, a existência de uma potência mimética formativa não de uma expressão morfológica do organismo, mas de uma configuração psíquica e, mais especificamente, egoica do indivíduo. Assim como é possível supor um circuito que conecte as formas e cores do meio com aquelas que são estampadas no corpo do animal que mimetiza, também é possível supor que os neurônios espelho reproduzam o próprio olhar, transformando o que era apenas um órgão sensível à luz em fonte de olhar. É preciso, no entanto, avançar um pouco mais na investigação sobre a metafísica do olhar para que estas indagações e suposições nos conduzam ao ponto em que queremos chegar.

A hipótese de que a imitação do olhar do outro participa do surgimento do eu suscita um problema quando colocada em conexão com a questão do visível e do invisível tal como pensada por Merleau-Ponty. O olhar, tomado como fator constitutivo do eu pelo outro, convida à suposição de uma agência de poder e controle incidindo soberanamente sobre os objetos do mundo. Nada mais distante do pensamento do autor de O visível e o invisível (1964), para quem existe um direito de pré-possessão (préemption) de toda a ordem do visível sobre o olhar. Ou seja, o olhar não incide sobre um caos, mas já encontra coisas visíveis, de tal forma que se torna necessário falar de uma prioridade do visível capaz de reverter a suposta autonomia do olhar numa forma de interrogação produzida pelo retorno ativo do objeto sobre o olhar; como se o visível tivesse sobre o vidente (le voyant) um efeito de intimidação. Trata-se aqui, na verdade, de um ponto de convergência dos pensamentos de Merleau-Ponty, Sartre e Lacan, na medida em que chegam, por diferentes vias, à mesma constatação de que somos olhados pelas coisas, tanto quanto as olhamos. Este eu que olha encontraria, portanto, um lugar mais adequado nesta metafísica do olhar se pudesse coincidir menos com a identidade pessoal e com as idiossincrasias de uma mente particular ou de um corpo e mais com a perspectiva de Merleau-Ponty, que tende a localizar na "carne do mundo" o ponto original da visão. O surgimento do eu se daria, assim, a partir de uma espécie de conexão de um aparato neurobiológico a uma potência de olhar impessoal e possivelmente suprabiológica, embora transmitida pela via da intersubjetividade. Sem fazer nenhuma referência à origem do eu e menos ainda à intersubjetividade, Lacan identifica em Merleau-Ponty os traços de uma busca das origens da visão bastante compatível com esta concepção de eu:

"Parece que vemos assim, nessa obra inacabada [O visível e o invisível], desenhar-se algo como a pesquisa de uma substância inominada da qual eu mesmo, o vidente 
(le voyant), me extraio. Das raias de uma armadilha, ou raios, se vocês quiserem, de uma cintilação (des rets, ou rais si vous voulez, d'un chatoiament) da qual de começo sou uma parte, surjo como um olho, ganhando, de algum modo, emergência por aquilo que eu poderia chamar a função da voyura (la fonction de la voyure)" (LACAN, 1973/1985a, p.81-83; 1973b, p.95)

Nossa própria maneira de pensar a pré-possessão do visível e a pré-existência do dado a ver sobre o olhar parte do reconhecimento da primazia de uma determinada forma a ser destacada de todas as demais que compõem o universo do visível. Trata-se da face e da proeminência dos olhos na composição desta Gestalt soberana. Se temos razão em destacar a forma dos olhos como algo decisivo na constituição psíquica, podemos supor que a marca insuperável dessa origem participa da superação do “caos” que o olhar nunca poderá divisar na medida em que se tornará o invisível, ou seja, aquilo a que Merleau-Ponty se refere em termos de contrapartida secreta do visível, ou de membrure que envolve o visível e à qual sua própria existência está apensa.

Uma precisão, porém, se impõe para que preservemos, nessa apropriação que fazemos da pré-possessão do visível, a originalidade da situação antropológica descrita por Merleau-Ponty. Para este autor, não há um sujeito como princípio das coisas, nem tampouco um mundo que condiciona o sujeito, mas um sujeito no meio das coisas, sem que isso queira dizer que o sujeito se encontre atolado (enlisé) no ser do mundo. Como assinala Assoun (2001, p.89), ao comentar essa parte de $O$ visível e o invisível, o sujeito se distingue continuamente do mundo por seu corpo e seu olhar, sem, no entanto, dele se separar. Mas tem sua origem atrás de si, em sua condição de olhado desde antes de poder apreender com o olhar este ponto a partir do qual ele é olhado.

Não se trata, portanto, no nosso caso, de afirmar que a forma soberana dos olhos na face humana condicione o sujeito, mas sim que os olhos, como suportes privilegiados do olhar, asseguram o lugar do sujeito no meio das coisas: se é verdade que o mundo me olha, que as coisas me interpelam ao invés de jazerem passivamente, é porque, de alguma maneira, elas se conectam com os olhos, mesmo que seja pelo fato mínimo de se apresentarem como uma forma, evocando assim uma forma primordial, que ao nosso ver é a forma dos olhos emoldurados pela face.

Pensar os olhos como uma forma primordial dada a ver requer que sejamos mais precisos quanto a essa forma. Se já deixamos claro que compartilhamos com Lacan e Merleau-Ponty a ideia de que algo cinde o olho e o olhar, resta ainda considerar a referência sartriana que influenciou esses dois autores, e nos posicionar quanto a uma questão decisiva, cujos desdobramentos estão presentes tanto na formulação de Merleau-Ponty de um "quiasma” que marca a relação 
entre o ver e o ser visto, quanto na proposição lacaniana da "schize" do olho e do olhar, a saber, a questão sobre a possibilidade ou não de ver os olhos em concomitância com a apreensão do olhar. Ademais, tocamos aqui num ponto a respeito do qual Lacan diverge explicitamente de Sartre, o que, em vista do nosso interesse, não poderia deixar de nos solicitar.

Sartre parece distanciar-se, num primeiro momento, da atribuição de uma primazia da forma dos olhos. Para ele, todo olhar se manifesta em conexão com o aparecimento de uma forma sensível em nosso campo de percepção, mas não se prende a nenhuma forma determinada. Embora admita que a convergência de dois globos oculares na direção de quem percebe o olhar seja a ocorrência mais frequente, insiste na possibilidade de que outras coisas representem os olhos e se prestem a suportar a função do olhar. Para o combatente que se esgueira entre arbustos no campo de batalha, a casa de fazenda no alto da colina é o ponto de origem do olhar que ele procura evitar (SARTRE, 1966, p.310). Sartre esclarece, no entanto, que a casa em questão não é o olhar propriamente; ela apenas representa os olhos, pois estes não são, no primeiro momento, apreendidos como órgãos sensíveis da visão, mas como suportes do olhar. Desta maneira, essa casa nunca se refere aos olhos concretos do inimigo que ali se encontra, uma vez que ela mesma já é olho.

Por outro lado, Sartre adverte que o olhar não pode ser reduzido a uma qualidade entre outras do objeto que faz a função dos olhos, nem tampouco à forma total desse objeto, e menos ainda a uma relação "mundana” que se estabelece entre o objeto e aquele que percebe o olhar. Isto significa que, ao contrário de ser percebido nos objetos que o manifestam, a apreensão do olhar que se dirige a alguém se faz sob a condição de uma destruição dos olhos de onde ele emana: quando se apreende o olhar, cessa-se de ver os olhos; o olhar do outro esconde seus olhos, conclui Sartre. A impossibilidade de que uma relação mundana se estabeleça entre o olhar e quem o percebe significa que o olhar do outro anula a distância que interponho entre mim e as coisas. Essa distância existe quando vejo os olhos do outro, mas se perde quando apreendo seu olhar. De alguma forma sou transformado pelo olhar do outro, e tenho anulado meu poder de me distanciar do que me olha.

Ao comentar as formulações de Lacan sobre o olhar no Seminário XI, PaulLaurent Assoun (2001, p.95) chama a atenção para um detalhe pleno de significados: a adoção entusiasmada da fenomenologia sartriana da apreensão do outro e da intersubjetividade, declarada desde o Seminário I, cede lugar, em 1964, a uma hesitação entre a reafirmação do "brilhantismo" (LACAN, 1973b, p.97) das ideias de Sartre e a refutação de uma de suas teses mais centrais. 
"Não é verdade que, quando estou sob o olhar, quando peço um olhar, quando o obtenho, não o vejo mais como olhar. [...] O olhar se vê — precisamente esse olhar que me surpreende, e me reduz a alguma vergonha, pois que é este o sentimento que ele [Sartre] esboça como o mais acentuado. Esse olhar que encontro - isto pode ser destacado no texto mesmo de Sartre - de modo algum é um olhar visto, mas um olhar imaginado por mim no campo do Outro." (LACAN, 1973/1985a, p.77; 1973b, p.89)

Para Assoun, o que determina o desacordo de Lacan é o fato de não mais lhe interessar uma concepção do olhar assentada na presença de um outro, semelhante, que me olha e me desloca do meu ponto de apreensão das coisas, impondo assim uma espécie de dialética intersubjetiva na qual Sartre apoia sua “ontologia nadificante". Em 1964, interessava-lhe uma alteridade na qual se conjugassem, de um lado, o desejo em sua relação estrutural com "a falta central simbolizada pelo fenômeno da castração” (LACAN, 1973/1985a, p.77; 1973b, p.89) e, de outro lado, este objeto especial, o olhar, que, ao contrário de sustentar o sujeito em sua relação com outro sujeito, promove sua aparição/aniquilação (où le sujet vient à choir). É, portanto, em sua relação com a "estranha contingência" que é "a falta constitutiva da angústia de castração" que o olhar se torna um objeto apto a sustentar a função do Outro. Lacan se distancia assim de uma alteridade que tende, em Sartre, a se confundir com uma transcendência — pois o olhar do outro me coloca no lugar de objeto e me destitui de meu poder objetivante, obstruindo, assim, toda relação "mundana" com o outro — , ${ }^{2}$ para reafirmar uma alteridade do Outro em sua relação estrutural com a falta e o desejo. A seguinte passagem esclarece este ponto:

"O olhar de que se trata é mesmo presença de outrem enquanto tal. Mas é de se dizer que, originalmente, é na relação de sujeito a sujeito, na função da existência de outrem como me olhando, que percebemos o de que se trata no olhar? Não estará claro que o olhar só intervém na medida em que não é o sujeito nadificante,

\footnotetext{
${ }^{2}$ Veja, por exemplo, a seguinte passagem: "na medida em que me experimento como olhado, realiza-se para mim a presença transmundana do Outro. O Outro me olha não como estando no meio do meu mundo mas como vindo, de toda sua transcendência, na direção do mundo e na minha direção; quando ele me olha ele não está separado de mim por nenhuma distância, por nenhum objeto do mundo — seja real ou ideal — por nenhum corpo no mundo, mas pelo único fato de sua natureza como outro. Assim, a aparição do olhar do Outro não é uma aparição no mundo — nem no 'meu' nem no 'do Outro' — e a relação que me une com o outro não pode ser uma relação de exterioridade dentro do mundo. Pelo olhar do outro eu efetuo a prova concreta de que existe um 'além do mundo'. O outro está presente para mim sem nenhum intermediário, como uma transcendência que não é a minha.” (SARTRE, 1966, p.361) (Tradução nossa. Grifos no original).
} 
correlativo do mundo da objetividade, que se sente surpreendido [pelo olhar do outro], mas um sujeito se sustentando numa função de desejo?

Não será justamente porque o desejo se instaura aqui no domínio da voyura que podemos escamoteá-lo?” (LACAN, 1973/1985a, p.84; 1973b, p.98)

Esta utilização que Lacan faz da situação analisada por Sartre, a saber, alguém que espreita através de um buraco de fechadura, desloca o foco existencialista no efeito nadificante que a própria ação de espreitar produz sobre o sujeito para projetá-lo numa outra forma de esvaziamento da subjetividade, que seria sua sustentação "numa função de desejo”, ou seja, a redução do sujeito aos efeitos da castração como falta estrutural. Enquanto Sartre parte de uma situação intersubjetiva, que pressupõe a existência de um outro que me olha, para chegar a uma transcendência, a uma presença "trans-mundana” do outro, Lacan parte da pressuposição de uma falta estrutural no Outro para chegar a uma função do olhar como objeto do mundo, porém puntiforme, evanescente, inapreensível, com o qual se confunde a própria falência do sujeito, ele também inapreensível e puntiforme.

Parece claro, portanto, que ao querer manter o olhar no campo do visível, assegurando-lhe o status de objeto, Lacan buscava uma vinculação da falta estrutural com um fenômeno localizável: “um objeto privilegiado, surgido de alguma separação primitiva, de alguma automutilação induzida pela aproximação mesma do real [...]"(LACAN, 1973/1985a, p.83; 1973b, p.96). O olhar como objeto a nos remete então a alguma experiência da história primitiva do sujeito, da qual tentaremos nos aproximar valendo-nos do apólogo com o qual Lacan pretende elucidar a "relação do sujeito com a luz" (LACAN, 1973/1985a, p.93; 1973b, p.109) e que é, na verdade, um relato sobre as vicissitudes do ver e do ser visto.

Comecemos pelo fim, pois ele nos parece decisivo para entender o que está apenas meio-dito. No episódio narrado, o jovem Lacan se descobre como mancha num quadro onde, ele mesmo reconhece, teria inicialmente se figurado como um bravo entre bravos pescadores da Bretanha pré-industrial. Mas das muitas formas possíveis de fazer mancha no quadro, aquela que lhe fora ali reservada esteve longe de lhe ser anódina, como atestam as reiteradas menções à desproporção entre a intensidade do riso dos que não eram mancha naquele quadro e o "menos" de graça que Lacan pôde encontrar na situação em que foi colocado. A julgar pela conclusão, quando se trata de dizer tudo sobre o inenarrável, a experiência da mancha foi também uma experiência de trauma:

“[...] eu, eu fazia quadro de uma maneira bastante inenarrável. Para dizer tudo, por mínimo que fosse, eu era mancha no quadro. E é mesmo sentir isto que faz 
com que, só por me ouvir interpelar assim, nessa humorística, irônica estória, não a acho tão engraçada assim" (LACAN, 1973/1985a, p.94; 1973b, p.110)

Joãozinho (Petit Jean), que se encontrava no pequeno barco de pesca no qual Lacan se aventurava, o interpela: “Tá vendo aquela lata? Tá vendo? Pois ela não tá te vendo não!" (LACAN, 1973/1985a, p.94; 1973b, p.110).

Permitam-nos reconstituir a cena da forma como achamos que pode ter acontecido: “Tu vois cette boite?”, pergunta Joãozinho, enquanto Jacques olha atento na direção da lata de sardinhas que espelhava ao sol (miroitait dans le solei), boiando entre as ondas. “Tu la vois?”, insiste Joãozinho, fazendo com que Jacques não só a olhe como também nela se concentre, a ponto de não ver outra coisa, e se esquecer de si e dos outros, enquanto se empenhava em ver naquele objeto algo além de uma simples lata de sardinhas. "Eh bien, elle...", Joãozinho anuncia uma espécie de revelação, levando Jacques ao extremo da expectativa: “...elle te voit pas!" "“la boite”, nós acrescentaríamos), dispara Joãozinho, que imediatamente começa a gargalhar e arranca Lacan de sua imersão. Do fundo de seu próprio riso amarelo, Jacques Lacan se descobre tache, ou seja, se dá conta de que fora hipnotizado, que se deixara dissolver no brilho (do olhar) da lata e na voz que o comandava até ser surpreendido em sua condição de assujeitado. Se a lata não o vê, embora, "num certo sentido, mesmo assim", ela o olhe (en un certain sens, tout de même, elle me regarde), não seria porque, ao fixar aquele olhar, Lacan teria se tornado A lata, ou seja, uma mancha cintilante no quadro ondulante do oceano?

Responder afirmativamente a esta pergunta significa admitir, com Sartre, que existe uma potencial destituição da capacidade de se distanciar das coisas do mundo inerente ao fato de ser objeto do olhar. Mas significa também ir um pouco além de Sartre e admitir que as coisas podem se apropriar do meu olhar, e, por meio dessa apropriação, produzir uma consciência que não seria mais minha, uma consciência colada nas coisas e nos atos.

Sartre nos fala ainda de outra forma de destituição de si mesmo ao explorar as vicissitudes da consciência no caso da pessoa surpreendida no ato de olhar pelo buraco da fechadura. Nesse caso, ele fala de uma presença de si como algo que não é dado diretamente a uma consciência reflexiva, para a qual ela seria um objeto, mas como uma presença indireta, pois depende de um outro para quem ela se torna um objeto. Tal situação configura um si mesmo que escapa de si mesmo, não porque seja autor de sua própria nadificação, mas porque tem sua fundação fora de si, visto que a percepção que tem de si resulta de ele ser uma pura referência para o outro. A incidência desse olhar que transforma o sujeito em objeto marca também a instauração da presença trans-mundana do outro, posto que seu olhar envolve o sujeito sem lhe deixar a possibilidade de tomar distância, impondo-se assim como um olhar impossível de ser localizado 
entre as coisas do mundo e que não comporta nenhuma intermediação. Sartre conclui que, pelo olhar do outro, o sujeito tem uma prova concreta da existência de um "fora do mundo", de uma transcendência. Institui-se assim uma relação sem reciprocidade na qual, ao mesmo tempo que o sujeito se torna objeto para um outro que o vê de certa distância, ele constata a impossibilidade de tomar distância desse olhar hors monde, que se impõe como transcendente. Seria então o caso de concluir que, tanto quando olhamos quanto quando somos olhados, corremos o risco de nos perder de nós mesmos? E qual seria então este estado do ser no qual somos lançados quando somos assim extraviados?

Tocamos aqui no que de fato nos interessa nessa surpreendente ontologia sartriana e na possibilidade de colocá-la em relação à teoria lacaniana do olhar como objeto a. Consideramos imprescindível poder preservar dois aspectos da metafísica do olhar aparentemente inconciliáveis, a saber: por um lado, a dimensão transcendente do olhar, esse hors monde de que fala Sartre, ou essa "substância inominada" que Lacan pôde identificar em Merleau-Ponty; por outro, sua dimensão mundana, não como uma banalização do olhar, de sua redução à simples apreensão dos olhos que me miram, mas no sentido, proposto por Lacan, de uma ocorrência especial, "induzida pela aproximação mesma do real”, localizável na história primitiva de cada sujeito e, ao mesmo tempo, capaz de remeter ao "trans-mundano", capaz de realimentar a transcendência.

Aquele cujo olhar tem o poder de abolir as distâncias e que ao mesmo tempo institui um "mim mesmo" inteiramente dependente de uma referência externa; este Outro, antes de se tornar hors monde, como sustenta Sartre, deve ser colocado em relação com um pequeno outro, mundano, cujo olhar incide sobre olhos dados a ver antes de poderem olhar. Num momento originário, em que os olhos não são ainda órgãos da visão, mas apenas de recepção passiva da luz, esse outro será o agente de um olhar que buscará um olhar ainda inexistente. Este olhar perscrutador, que incide sobre os olhos do bebê, está fadado a ser imitado, para ser, então, imediatamente perdido como olhar para aquele que passa, assim, a ver. Mas o que o bebê agora vê são os olhos se destacando na face, forma que se torna assim fundamental por se instituir como um resto morfológico do objeto que só é visível quando ainda não há um eu, quando ainda não se sabe ver: o olhar originário cujo brilho fugidio torna-se assim passível de ser refletido em todas as coisas, transformando-as em videntes potenciais, marcando-as com a transcendência da voyure.

Recebido em 24/8/2009. Aprovado em 29/4/2010. 


\section{REFERÊNCIAS}

ASSOUN, P-L. (2001) Le regard et la voix, leçons de psychanalyse, Paris: Anthropos.

GADDINI, E. (1969) On imitation, International Journal of Psychoanalysis, v. 50, p.475-484.

LACAN, J. (1973/1985a) O seminário, livro 11, Os quatro conceitos fundamentais da psicanálise. Rio de Janeiro: Jorge Zahar.

(1973b) Le Séminaire, livre 11, Les quatre concepts fondamentaux de la psychanalyse. Paris: Seuil.

GAWRYSZEWSKI, L. G., LAMEIRA, A. P., FERREIRA, F.M., GUIMARÃESSILVA, S., CONDE, E.F.Q., PEREIRA, J. R. (2006) Neurônios espelho, Psicologia USP, 17(4), 123-133.

MERLEAU-PONTY, M. (1964) Le visible et l'invisible. Paris: Gallimard.

RIZZOLATI, G. FOGASSI, L. GALLESE, V. (2000) "Cortical mechanisms subserving object grasping and action recognition: a new view on the cortical motor functions", in GAZZANIGA, M. S. (Org.) The cognitive neurosciences. Cambridge MA: MIT Press.

(2001) Neurophysiological mechanisms underlying the understanding and imitation of action, Nat Rev Neuroscience, 2, 661-70.

SARTRE, J-P.(1966) L'Être et le Néant. Paris: Gallimard.

SCALZONE, F. (2005) Notes for a dialogue between psychoanalysis and neuroscience, International Journal of Psychoanalysis, v.86, p.1.405-23.

Paulo de Carvalho Ribeiro

Icaro.bhz@terra.com.br 